ENCYCLOPEDDIE Encyclopédie berbère

BERBERE

$23 \mid 2000$

23 | Hiempsal - Icosium

\title{
Ibn Toumart
}

E.B.

\section{OpenEdition}

Journals

Édition électronique

URL : http://journals.openedition.org/encyclopedieberbere/1629

DOI : 10.4000/encyclopedieberbere.1629

ISSN : 2262-7197

\section{Éditeur}

Peeters Publishers

\section{Édition imprimée}

Date de publication : 1 octobre 2000

Pagination : 3604-3606

ISBN : 2-7449-0207-1

ISSN : 1015-7344

Référence électronique

E.B., «Ibn Toumart », Encyclopédie berbère [En ligne], 23 | 2000, document 111, mis en ligne le 01 juin 2011, consulté le 24 septembre 2020. URL : http://journals.openedition.org/encyclopedieberbere/1629 ; DOI : https://doi.org/10.4000/encyclopedieberbere.1629

Ce document a été généré automatiquement le 24 septembre 2020

(c) Tous droits réservés 


\section{Ibn Toumart}

E.B.

1 Ibn Toumart est la personnalité religieuse et politique la plus marquante du Maghreb au XII ${ }^{e}$ siècle. Fondateur du mouvement almohade*, il devait préparer la revanche des Sanhadja montagnards contre l'empire déjà vacillant des Almoravides. Bien que ses disciples aient manipulé sans vergogne sa généalogie pour le rattacher à la descendance du Prophète et en faire, donc, un chérif, il est sûr qu'Ibn Toumart était issu d'une tribu du Sous, celle des Hergha, appartenant au groupe montagnard des Maçmouda.

2 L'un de ses premiers disciples, le pieux el Baïdaq, se fit son chroniqueur et grâce à son récit, souvent dithyrambique, il est possible de saisir l'évolution spirituelle de celui qui devait mériter le titre de Mahdi Almohade et le qualificatif d'Impeccable. Célèbre dès son adolescence, pour son zèle religieux et son érudition qui lui avait fait donner le surnom d'asufu (le tison, le flambeau, en berbère), Ibn Toumart quitta un beau jour son village d'Igliz et ses montagnes pour compléter, en Orient, sa connaissance de l'islam et jeter les bases d'une réforme radicale.

3 Son séjour en Espagne n'est pas assuré, mais demeurent des concordances étroites entre les textes d'Ibn Hazm et ses propres propositions. En revanche, sa présence à Bagdad est pleinement confirmée, alors que son passage à Damas est peut-être légendaire et les entretiens qu'on lui prête avec Ghazali certainement inventés.

4 Dix ans après son départ d'Igliz, Ibn Toumart entreprend un long voyage de retour au Maghreb, au cours duquel il multiplie les étapes, passant par Alexandrie, Tripoli, Mahdia, Tunis, Constantine et Béjaia. Sa condamnation des mœurs citadines relâchées provoque souvent des échauffourées. A Béjaia, ses violences verbales déclenchent la fureur populaire contre lui. Le sultan hammadite, qui l'avait d'abord bien accueilli, lança ses sicaires à sa poursuite, mais Ibn Toumart trouva refuge dans la tribu voisine, celle des Beni Urigol, dans le village de Melala. 


\section{La doctrine almohade}

5 Ibn Toumart y élabore sa doctrine et réunit ses premiers disciples. Le plus cher à son cœur, celui qu'il considère comme l'homme providentiel qui doit lui succéder, est Abd el Moumen, le fils d'un potier de Nédroma (Algérie occidentale). El Baïdaq nous a laissé le récit émouvant de la désignation du futur calife. Le réformateur proclama un soir en prenant sa main : "La mission sur laquelle repose la vie de la religion ne triomphera que par Abd el Moumen ben Ali, le flambeau des Almohades." Celui-ci, en pleurant, dit avec humilité : "Ô Maître, je n'étais nullement qualifié pour ce rôle, je ne suis qu'un homme qui cherche ce qui pourra effacer ses péchés." - "Ce qui te purifiera de tes péchés, répondit Ibn Toumart, ce sera précisément le rôle que tu joueras dans la réforme de ce monde."

6 Une conversation avec deux pèlerins de l'Atlas qui passaient par Bougie est l'occasion du départ des premiers Almohades vers le Maghreb el Aqsa. La petite troupe, d'une dizaine de personnes, gagne Marrakech non sans avoir semé la bonne parole et causé quelques troubles dans les villes traversées : Tlemcen, Oujda, Taza, Fès, où Ibn Toumart se fait remarquer par le saccage des magasins des marchands de musique, contre lesquels il semble avoir eu une aversion certaine. Il réitère à Marrakech, brisant à coups de bâton instruments de musique et jarres de vin, pourchassant sous les huées la sœur de l'émir almoravide, qui chevauchait dévoilée dans les rues de la capitale.

7 Après la prise de Tin Mel (1123), il se proclame Mahdi et, de retour dans les tribus Masmouda, ses frères de race, il organise solidement la communauté almohade avec un soin et une connaissance des hommes qui font de ce clerc un grand homme d'État. Il crée un véritable État montagnard, solidement organisé, disposant d'une armée fanatisée chargée de répandre la doctrine almohade jusqu'en Ifriqiya et en Espagne.

8 Nous retrouvons dans cette réforme la même tendance innée vers le rigorisme moral et la simplicité doctrinale que nous ont révélés tous les schismes et hérésies nés en Berbérie à travers les siècles.

9 Dans la condamnation absolue des richesses de ce monde et de ses frivolités, c'est la voix d'Ibn Toumart qui tonne, mais elle fait écho à celle, non moins véhémente, de Tertullien. La lente marche des Berbères vers le Dieu unique semble ici se parachever dans la proclamation de l'Unicité absolue de Dieu, dont Ibn Toumart rejette jusqu'aux adjectifs (le Puissant, le Miséricordieux, le Victorieux) que lui dorment les musulmans, parce qu'ils risquent de faire apparaître comme divisible la puissance divine. La conséquence inévitable de la toute-puissance de Dieu ainsi comprise est la prédestination de tous les êtres créés : chacun doit attendre dans la soumission totale ce qui lui a été assigné de toute éternité.

10 Cette forme de l'islam ne peut qu'être fanatique, elle ne supporte ni relâchement des mœurs, ni relativisme dans le dogme, ni présence d'Infidèles.

11 Ces données concordaient trop bien avec l'intransigeance fondamentale des Berbères pour ne pas aboutir : aussi, sous Abd el Moumen, le raz de marée almohade balaya le Maghreb de toute impureté. C'est alors, semble-t-il, que disparurent les dernières communautés chrétiennes autochtones. 


\section{L'État almohade}

12 Respectueux des traditions tribales des Berbères du Haut Atlas, Ibn Toumart organisa son gouvernement en établissant une hiérarchie entre différents conseils imités des assemblées tribales. Au sommet siège le Conseil des Dix, qui sont les premiers et les plus fidèles compagnons (Abd el-Moumen*, Abou Hafs Omar*, El Bachir...). Au-dessous du Conseil des Dix, le Conseil des Cinquante est composé de contribules d'Ibn Toumart, des Hergha et d'autres Maçmouda de Tin Mel ou des Hintata. Les différentes tribus de la montagne étaient ainsi représentées dans ce Conseil dont les pouvoirs étaient restreints.

13 Toute la société almohade était strictement hiérarchisée. A l'intérieur des groupements ethniques apparaissait une autre hiérarchie, fondée sur les fonctions exercées, depuis celles des compagnons les plus proches jusqu'à celles confiées aux abid (serviteurs noirs). Au sommet de la pyramide, le Mahdi tenait solidement les rênes d'un pouvoir absolu. Cette domination reposait sur une logique implacable : tout Almohade suspecté de tiédeur risquait l'élimination: ainsi lors de la "journée du tri" plusieurs milliers d'almohades "infidèles" furent massacrés. C'est par de telles actions qu'Ibn Toumart réussit à construire l'État almohade et à assurer la naissance de la nouvelle dynastie moumenide. Seuls le prestige et la volonté d'Ibn Toumart réussirent à faire admettre Abd el-Moumen comme le successeur désigné du Mahdi. Encore fut-il nécessaire de cacher la mort de celui-ci pendant plus de deux ans avant de faire reconnaitre le nouveau souverain par les Cheikhs almohades.

\section{BIBLIOGRAPHIE}

Voir E.B., A 170, Almohades ; A 210, Abd al-M’umin.

BASSET R., "Ibn Toumart”, Encyclopédie de l'islam.

BEL A., “Documents récents sur l'histoire des Almohades”, Revue africaine, t. 71, 1930, p. 113-128.

BEL A., La religion musulmane en Berbérie.

EL MARRAKOCHI, Histoire des Almohades, traduction Fagnan, Revue africaine, 1891-1892.

GAUDEFroy DEMONBynes, "Une lettre de Saladin au calife almohade", Mélanges R. Basset, II, p. 279-304.

IBN KHALDOUN, Histoire des Berbères, trad. de Slane, t. II.

LE TOURNEAU R., The almohade movement in North Africa in the twelfth and thirteenth centuries, Princeton, 1961.

MARÇAIS G., La Berbérie musulmane et l'Orient au Moyen Âge, Paris, Albin Michel, 1946.

TERRASSE H., Histoire du Maroc. 
INDEX

Mots-clés : Moyen Âge, Personnage, Religion 